S a mmlung Göschen B and 66

\title{
Russische Grammatik
}

Von

\author{
Dr. Erich Berneker
}

ord. Professor an der Universität München

Sechste, unveränderte Auflage

Von

Dr. Max Vasmer

ord. Professor an der Universität Berlin

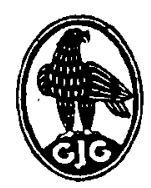

W a $1 \mathrm{t}$ e $r$ d e $G r u y t e r \&$ C 0 . vormals G. J. Göschen'sche Verlagshandlung - J. Guttentag, Verlagsbuchhandlung · Georg Reimer - Karl J. Trübner · Veit \& Comp.

Berlin 1947 
Alle Rechte, insbesondere das Ubersetzungsrecht, von der Verlagshandlung vorbehalten

Archiv-Nr. 110066

Gesamtherstellung von J.J. Augustin, Glückstadt

Printed in Germany 